\title{
Health Disparities in Kidney Transplantation for African Americans
}

\author{
Kimberly Harding a Tesfaye B. Mersha ${ }^{b}$ Phuong-Thu Pham ${ }^{c}$ \\ Amy D. Waterman ${ }^{c}$ Fern J. Webb ${ }^{\mathrm{e}}$ Joseph A. Vassalottif ${ }^{\mathrm{f}}$ \\ Susanne B. Nicholas ${ }^{\mathrm{d}}$ \\ ${ }^{a}$ Monarch Innovation Partners, Inc., Rockville, MD, b Department of Pediatrics, Cincinnati Children's Hospital \\ Medical Center, University of Cincinnati, Cincinnati, $\mathrm{OH},{ }^{\mathrm{C}}$ Division of Nephrology, and ${ }^{\mathrm{d}}$ Division of Nephrology and \\ Division of Endocrinology, Department of Medicine, David Geffen School of Medicine at University of California, \\ Los Angeles, CA, e University of Florida College of Medicine Department of Community Health and Family Medicine, \\ Jacksonville, FL, and f National Kidney Foundation, Inc., and ${ }^{9}$ Division of Nephrology, Department of Medicine, \\ Icahn School of Medicine at Mount Sinai, New York, NY, USA
}

\section{Keywords}

Kidney transplantation - Health disparities - African American · Donor · Outcome - Gene variants · Call to action · Education

\begin{abstract}
Background: The persistent challenges of bridging healthcare disparities for African Americans (AAs) in need of kidney transplantation continue to be unresolved at the national level. This healthcare disparity is multifactorial: stemming from limited kidney donors suitable for AAs; inconsistent care coordination and suboptimal risk factor control; social determinants, low socioeconomic status, reduced access to care; and mistrust of clinicians and the healthcare system. Summary: There are numerous opportunities to significantly lessen the disparities in kidney transplantation for AAs through the following measures: the adoption of new care and patient engagement models that include education, enhanced practice-level cultural sensitivity, and timely referral as well as increased research on the impact of the environ-
\end{abstract}

\section{KARGER}

E-Mail karger@karger.com

www.karger.com/ajn ment on genetic risk, and implementation of new transplantation-related policies. Key Messages: This systematic review describes pretransplant concerns related to access to kidney transplantation, posttransplant complications, and policy interventions to address the challenging issues associated with kidney transplantation in AAs.

(c) 2017 S. Karger AG, Basel

\section{Introduction}

Kidney transplantation is the optimal renal replacement therapy for eligible patients with end-stage renal disease (ESRD) as it offers the best quality of life with lowest rates of morbidity and mortality. Greater than $50 \%$ of patients awaiting kidney transplantation in the United States are ethnic minorities with African Americans (AAs) constituting $>33 \%$ of those on the waiting list [1]. Despite the substantial advancements in kidney transplantation, significant disparities still exist between AAs and Caucasian Americans (CAs), including longer time 
on the transplant waiting list, increased incidence of new onset diabetes after transplant, lower access to live donor kidney transplants (LDKT), and lower rates of graft survival. In addition, over the past 10 years, the rate of kidney transplants from deceased donors for Blacks, compared to Whites, has remained low [2]. Despite a slower decline in delayed graft function and overall increase in rates of living donation, evaluation of 1990-2009 registry data revealed that AAs had waited 76.5 more mean days longer per 5 years on the waiting list and experienced a $3.4 \%$ increased relative risk of 5 -year graft loss compared to CAs [3].

Reduced access to kidney transplantation for AAs relative to CAs has been extensively documented in recent decades with a complex array of contributors, including patient preferences, clinician biases, poor patient education, as well as low socioeconomic status (SES), inadequate health insurance, more frequent contraindications to transplantation, low rates of deceased and living kidney donation among AAs, and immunologic factors. Two retrospective studies showed that AAs were less likely to complete a kidney transplant evaluation than CAs $[4,5]$. Indeed, reduced access to kidney transplantation is the most serious disparity in ESRD because it limits duration and quality of life. The current review describes factors that contribute to the racial disparities in kidney transplantation among AAs prior to transplantation, donorrelated issues, the impact of disparities on kidney transplant outcomes and recommendations that may reduce these disparities.

\section{Racial Disparities in Access to Transplant among AAs: Pretransplant Concerns}

Risk factors or barriers for racial disparities in access to kidney transplantation among AAs versus CAs may be classified as recipient-related, donor-related, and clinician-related factors. For clinician-related factors, both late and lower referral rates play important contributory roles. A preliminary analysis of a single-center study showed that in the first 9 months following the implementation of the new kidney allocation system (KAS), during which time, points were awarded for time spent on dialysis, access to deceased donor kidney transplantation improved for minorities. These findings suggested that waitlisted minorities were likely referred for transplantation later in their course of ESRD and got transplanted faster under the new allocation system based on dialysis vintage [6].
The lower rate of referral for kidney transplantation among AAs is also thought to be due in part to lack of education and information about the risks and benefits of transplantation on the part of the healthcare practitioner. A delay in referral has been attributed to the complacency among clinicians to refer AAs for transplantation because AAs reportedly have better quality of life and are more content on dialysis compared to their CA counterparts [7]. Leggat et al. [8] reported that after adjusting for age and diabetic status, Black patients with ESRD voluntarily withdrew from dialysis at only approximately half the frequency of Whites. In addition, low SES minorities are more likely to receive care from physicians who are less knowledgeable in specialized areas including organ transplantation. Racial disparities can also result from clinicians' misinterpretation of patients' indecision about transplantation as lack of interest. In another study, patients suggested that financial incentives may have motivated some physicians to withhold information about transplantation to keep their patients on dialysis [9].

Further, there were fewer AA living donors as shown in the previously mentioned study between 2003 and 2009 [3], making this a donor-related factor that reduces the likelihood of allocation to AA recipients overall.

Patient-related causes for racial disparities in access to transplantation are multifactorial and include lack of psychosocial support, misconceptions about the risks to recipients and donors, mistrust about equity in the organallocation process, inadequate insurance or low SES, and medical unsuitability. Medically, the severity of illness, incidence of diabetes, obesity, and comorbidities are higher among AAs compared with CAs. Although no consensus exists, at the authors' institutions, a history of mild hypertension may be acceptable for donation if the prospective donor meets the following 5 criteria: (1) $>50$ years of age, (2) no evidence of microalbuminuria or endorgan damage, (3) normal glomerular filtration rate for age, (4) well-controlled blood pressure with lifestyle and behavioral modifications or on a single antihypertensive agent, and (5) non-AA. However, prospective donors with fasting glucose level, oral glucose tolerance test, or A1C in the prediabetic range are frequently denied the opportunity to donate if they are AA, whereas their nonAA counterparts are generally being considered for kidney donation on a case-by-case basis.

Other putative factors that may impact access to transplantation include patient preferences, lack of certainty about desire to undergo transplantation versus remaining on dialysis, low health literacy, poor psychosocial support
166

Am J Nephrol 2017;46:165-175 DOI: $10.1159 / 000479480$
Harding/Mersha/Pham/Waterman/ Webb/Vassalotti/Nicholas 
while undergoing dialysis, interactions with medical professionals of other ethnicity, and valid concerns about kidney transplant-related issues. In a single-center study using qualitative strategies to explore perceptions of dialysis and kidney transplantation among AAs undergoing dialysis, females ( $<65$ and $\geq 65$ years) and older males ( $\geq 65$ years) reported more support from friends and/or family compared with their younger male counterparts [9]. Hence, females and older males may have a more positive attitude toward continuing dialysis with less interest in pursuing transplantation versus their younger male counterparts. The study also demonstrated lack of knowledge about kidney transplantation among all participants regardless of age or gender. For example, some patients have quoted: "the biggest problem is that not enough information is available, and available timely, so that people have a chance to think and digest and maybe talk about it with other people before they make those kinds of decisions regarding transplant", and "doctors need to tell us the pros, the cons, the results, and what could happen, and what could not happen". Participants also expressed feelings of being treated poorly by medical professionals. Other common concerns included increased pill burden, fear of surgery, fear of organ rejection, fear for donors, and older age (among older participants) [9].

Importantly, the lack of communication between patients, physicians, and the transplant center should not be overlooked [10]. A single-center survey study using the dialysis patient transplantation questionnaire revealed that $52.9 \%$ (18 of 34 ) of patients (age 18-34 years) who were undergoing transplantation evaluation were unaware of their listing status [11]. Of these patients, $88.9 \%$ (16 of 18) mistakenly thought they were listed and 11\% were unsure of their listing status. Among 32 wait-listed patients, $81.3 \%$ correctly identified themselves, $6.2 \%$ mistakenly thought they were not listed, and $12.5 \%$ were unsure. All the waitlisted patients were not aware that their listing status was status 7 , indicating they were temporarily inactive because they required additional testing or developed intercurrent illnesses. Nearly two-thirds of the patients surveyed had completed high school and 11\% had some level of college education, signifying a reasonably educated group. Notably, $82.8 \%$ of the study population was AA. The finding of a substantial lack of listing status awareness suggests lack of communication between the transplant program, patients, and referring nephrologists.

Persistent mistrust and misconceptions among AAs regarding the kidney transplantation process, risks to the recipients and donors as well as equitable allocation of al-

Kidney Transplantation in AAss lografts have contributed to the perceived reduced interest in kidney transplantation of many AAs receiving hemodialysis [10]. The source of this mistrust can be traced to past wounds of skepticism that have continued across generations of racism regarding access to and quality of care. In the early 1900s, the United States Federal government and state-level authorities systematically supported the Eugenics movement that arose out of a need "to improve the natural, physical, mental and temperamental qualities of the human family" [12]. The movement promoted interest in the inheritance of undesirable traits, such as pauperism, mental disability, dwarfism, promiscuity, and criminality that fueled sterilization laws in 35 states. In addition, forced sterilization of one-third of the $>60,000$ people in United States state-run homes and hospitals included institutionalized inmates afflicted with "various grades of feeblemindedness", "perversion or marked departures from normal mentality or disease from a syphilitic nature", and targeted noninstitutionalized individuals, which also included many AA women, under the guise of family planning $[13,14]$. Indeed, AAs were specifically targeted in the Eugenics sterilization of North Carolina between 1958 and 1968 [13]. Forced sterilization in California in the 1950s was deemed a prophylactic public health strategy to eliminate undesirable defects from the population, in order to strengthen the state [14]. Obviously, there was no scientific basis for the Eugenics movement, but it resulted in population-based posttraumatic stress that may have had a far-reaching contribution to the development of mistrust of the authority, including clinicians and healthcare systems for many AAs.

\section{Racial Disparities in Living Donor Kidney Transplantation among AAs}

There are many complex, inter-related reasons to the racial disparity in living donor kidney transplantation among AAs. For example, studies using structured interviews suggest that both recipients and donors faced barriers in the LDKT experience. Some ESRD patients remained in denial about the severity of their kidney disease or turned to faith as a sole coping mechanism. Others wished to maintain the privacy of their health status, hesitated to approach potential donors, or declined living donor offers. From the donor's perspective, prospective living donors may be challenged with barriers created by their own friends, family, and even the intended recipients. Many potential donors have reported having to de-

Am J Nephrol 2017;46:165-175 DOI: $10.1159 / 000479480$ 
fend themselves from friends and family who persistently question their wisdom in donating. Negative responses from everyone involved can deter living donation. Interestingly, idolization of the living donation process has been reported to create an uneasy or embarrassing feeling among potential donors [15].

Studies have also shown that among prospective living donors who initiated the living donor evaluation process, AAs were found to have a higher likelihood of ABO or cross-match incompatibility with their intended recipients, a higher body mass index, and other medical conditions that preclude donation [16]. AAs were also found to be more likely to be lost to follow-up or they stop pursuing live donation after donor evaluation process initiation. In general, AAs have higher rates of developing post-donation chronic kidney disease (CKD) due to hypertension and use of anti-hypertensive medication compared to CA donors (152-154). AA living kidney donors, especially AA women, compared to Whites have a higher risk of renal function decline postdonation [17], particularly individuals with a genetic predisposition. Indeed, the presence of 2 apolipoprotein L1 kidney risk alleles (APOL1) risk variants has been shown to increase the 25-year renal risk for 18-year-old AAs without baseline abnormalities (1.46\% for women; $2.53 \%$ for men) and for those with baseline abnormalities (from 2.53 to $6.23 \%$ for women and from 4.35 to $10.58 \%$ for men) [18]. Although, few centers offer APOL1 genetic screening, the increased risk for developing postdonation CKD may thus impact the potential donor's eligibility or willingness to donate. Therefore, education on factors potentially related to post-donation CKD should be part of the donor evaluation process [19], as is also suggested by Kidney Disease Improving Global Outcomes [20].

Lower education levels, and lack of behavioral skills to facilitate donation discussions with others may account for racial inequities in LDKT. In a study evaluating the effectiveness of educational interventions in removing barriers to LDKT, Rodrigue et al. [21] demonstrated a trend toward improvement in LDKT among Blacks randomized to receive education by a health educator in the patient's home or house call (HC) in the presence of his/ her guests compared with Blacks randomized to receive group-based (GB) or individual counseling (IC) at the transplant center. Although not statistically significant in this small study, at the 2-year endpoint, $15 \%(n=8), 8 \%$ $(n=4)$, and $6 \%(n=3)$ of HC, GB, and IC patients, respectively, received LDKT $(p=0.30)$. On the other hand, patients in the HC group were significantly more likely than patients in the GB and IC groups to have at least one donor inquiry ( 82 vs. 61 vs. $47 \%, p=0.001$ ) and evaluation ( 65 vs. 39 vs. $27 \%, p<0.001$ ). Furthermore, patients in the HC group were more likely to have higher knowledge, fewer concerns, and higher willingness to talk to others about donation 6 weeks after intervention [21]. The study findings suggest an important role for social network to encourage the participation of potential donors in initiating the process of LDKT.

\section{Disparities in Posttransplant Outcomes among AAs}

Graft and patient survival among recipients of solid organ transplants have been shown to be highest for Asians and Hispanic/Latinos, intermediate for CAs, and lowest for AAs [22]. Such racial disparity in outcomes is due in part to higher immunological risk among AAs leading to higher acute rejection rates and graft loss from acute and/or chronic rejection [23]. Suggested immunological risk factors common among AAs include HLA mismatches, higher panel reactive antibodies, immune hyper-responsiveness, genetic polymorphism in cytokine production, and more rapid immunosuppressant metabolism [3]. Recent studies suggest that gene variants may contribute to racial disparity in posttransplant outcomes $[24,25]$.

The 2 APOL1 kidney risk alleles, which co-evolve and protect African ancestry individuals from sleeping sickness, predispose AAs to the risk of developing ESRD and reduce allograft survival in AA recipients of AA donor kidneys [24]. However, in a recent editorial, Chandraker [26] surmised that there are insufficient data to recommend testing all AA potential donors with the aim of excluding individuals with both APOL1 risk variants. Similarly, Ojo and Knoll [27] concluded that APOL1 genotypes should not be currently used to guide the allocation or consent processes for kidneys from deceased organ donors. Although screening AA living kidney donors for APOL1 gene variant is currently not routinely performed, such screening and excluding those with 2 APOL 1 risk alleles may have the potential to further increase existing disparities between AA individuals and European Americans, since AAs might be more likely to have the APOL1 gene variant and thus more likely to be excluded as a potential donor. In addition, knowing one's APOL1 status might further impact one's decision to not become a donor. Nonetheless, the presence of 2 APOL1 risk alleles alone should not exclude an individual from being a prospective donor, but they should
168

Am J Nephrol 2017;46:165-175 DOI: $10.1159 / 000479480$
Harding/Mersha/Pham/Waterman/ Webb/Vassalotti/Nicholas 
be counseled regarding the risk of CKD/ESRD following kidney donation.

AAs also experience higher rates of infectious diseases, such as HIV-AIDs, viral hepatitis, and tuberculosis that may impact suitability for kidney donation and reduce survival. Specifically, in 2013, the Center for Disease Control and Prevention reported that AAs represented 43\% of all HIV cases in the United States; had the highest rates of, and were 3 times more likely to die from hepatitis B, compared to non-Hispanic Whites [28]. Other suggested factors predicting inferior outcomes among AAs include pretransplant dialysis vintage, which is a known risk factor for reduced patient and graft survival, lower income, reduced access to healthcare, more comorbid conditions, and higher medical nonadherence [29]. It is well-established that AAs are disproportionately affected by hypertension, diabetes, and obesity, compared to CAs, which increases their coronary heart disease risk [30] and hence negatively impacts posttransplant outcomes [31]. In addition, posttransplant outcomes in AAs may potentially be impacted by nonadherence to medications. In an early study, Foster et al reported that noncompliance accounted for 22 vs. $5 \%$ of graft loss in AA vs. non-AA recipients [23]. In another study, adherence and Black race were not shown to be highly associated with either acute rejection or reduced estimated glomerular filtration rate over time [32]. The race-adherence relationship was examined in a prospective cohort of 278 transplant recipients with deceased donor transplants [33]. The study showed that while the Black race was strongly associated with lower adherence (unadjusted, OR $0.43, p=0.0001$ ), the relationship was diminished when the data were adjusted for transplant center and medication dosing frequency. Randomized controlled trials (RCTs) specifically designed to investigate disparities in transplant outcomes in AAs due to nonadherence to medication may provide further insight into these relationships, and intervention possibilities.

Other risk factors for inferior posttransplant outcomes include lower bioavailability of cyclosporine and tacrolimus associated with cytochrome P450 3A5 polymorphism observed in AAs [34]. As a result, AAs suffer from more acute rejection episodes and decreased graft and patient survival. Nonetheless, testing for cytochrome P450 $3 \mathrm{~A} 5$ polymorphism is not readily available and it is unlikely that the pharmacogenetic findings will be adopted into clinical practice. Currently, most transplant centers perform single antigen testing in kidney transplant recipients with high immunological risk. Patients with donor-specific antibodies are managed with intensification

Kidney Transplantation in AAss of immunosuppression, and most transplant centers set tacrolimus and cyclosporine goal levels higher for AAs than for CAs after adjustment for immunological risks [35].

\section{Call to Action}

A multipronged approach is necessary to increase the rates of kidney transplantation and improve survival and overall quality of life among eligible AAs. Priorities for research and related interventions to reduce racial disparities in kidney transplantation between AAs and CAs patients have been comprehensively summarized in recent literature, including reports from a 2014 American Society of Transplantation (AST) Consensus Conference on Best Practices in Living Donation, which identified reduction in racial disparities in LDKT as a high priority [36-38]. Other areas that may be targeted include patient and potential donor education, and timelier transplant referral from the nephrologist. Figure 1 provides a conceptual model of the factors driving the racial disparities described in the review, as a foundation of interventions detailed in the following sections.

\section{Increase Patient Education}

It is critical to improve transplant education aimed at patients, potential donors, and providers in transplant and dialysis centers and expand the donor pool for minorities [36, 39]. Interventions that educate patients about LDKT are especially important since LDKT is an underutilized but an optimal treatment method for kidney failure, which might allow patients to overcome barriers associated with the deceased donor kidney transplant (DDKT) waitlist.

The assessment of whether or not an intervention actually reduces racial disparities is essential. Indeed, many interventions have demonstrated effectiveness for the general at-risk population, but paradoxically increased racial disparities for AAs and other racial/ethnic minorities who were unable to access and benefit from various interventions as easily as CAs [40]. Not only do AAs have reduced access to care, but they also likely have reduced access to clinical trials research. Because racial and ethnic minority patients are often less likely to receive education about transplantation options, they may also be less knowledgeable about transplantation facts, risks, and benefits [41, 42]. Further, although the AST Consensus Conference recommended transplant eligible patients with advanced CKD as well as those

Am J Nephrol 2017;46:165-175

DOI: $10.1159 / 000479480$ 
Fig. 1. Conceptual framework showing the convergence of factors that drive racial disparities among African Americans.

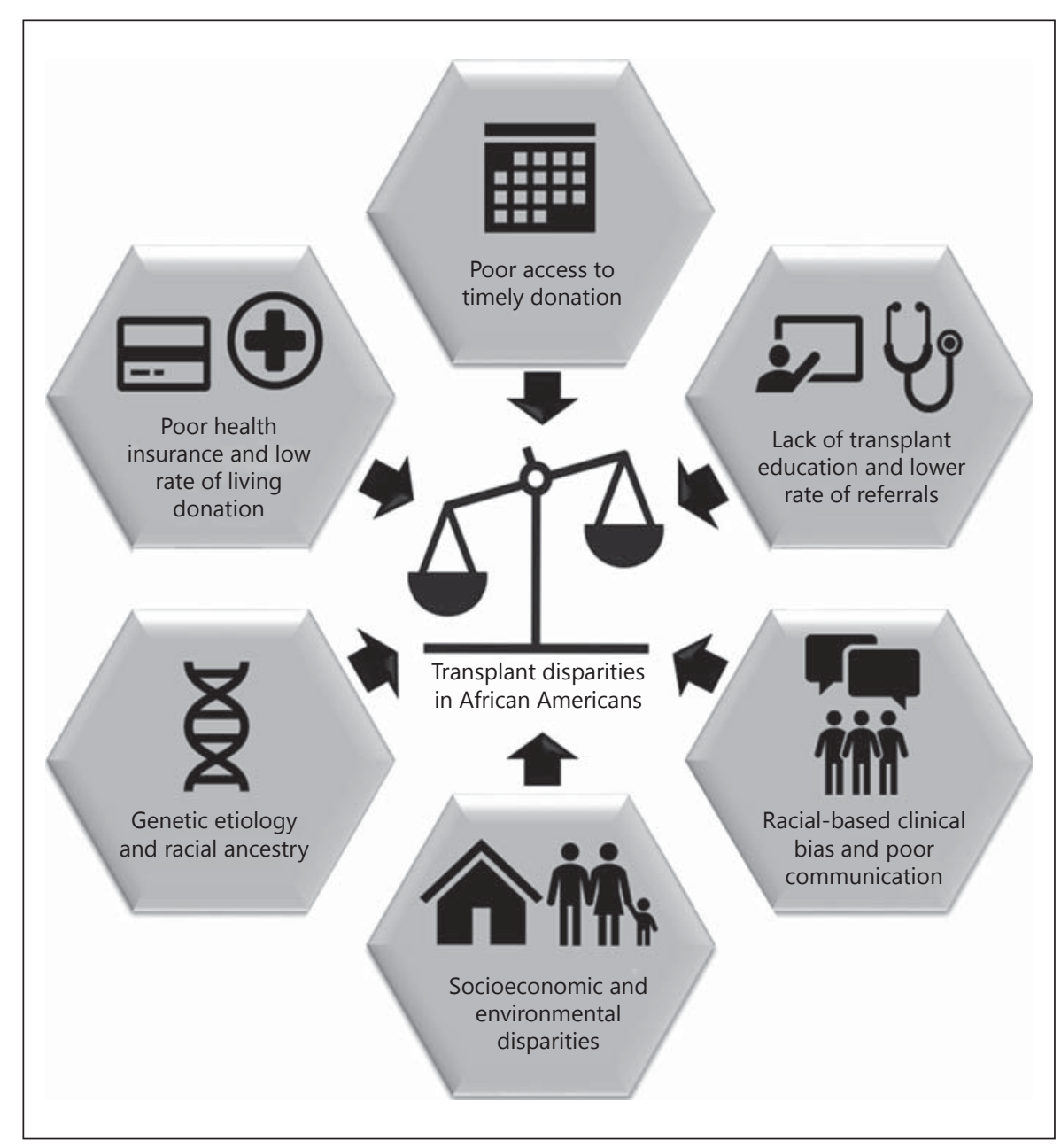

treated with dialysis and their clinicians receive comprehensive LDKT education, the specific education strategies to ensure patients learn about the kidney transplant option, as well as increase transplant rates, have not yet been identified [37, 43]. However, a number of RCTs and observational studies have demonstrated the efficacy and effectiveness of transplant education programs and offer guidance as to how racial disparities in transplant, especially LDKT, might be reduced among ESRD patients.

As previously mentioned, one of the better-studied transplant education programs designed to reduce racial disparities is the $\mathrm{HC}$ approach, pioneered by Rodrigue et al. [21, 44], which combines patient and group discussions with standardized educational materials. This approach is hypothesized to reduce potential mistrust and discomfort AA patients may have with usual medical settings [45]. Two RCTs examined whether this approach reduces racial disparities in learning about, attitude to- ward, and actual pursuit of LDKT [46]. In addition to the $\mathrm{HC}$ approach being effective for all patients in the first study [44], its effect on increasing living donor evaluations and receipt of LDKT was stronger for Black patients when compared to that of Whites [46]. The second study, conducted with Black patients only, resulted in a greater likelihood of living donor inquiries and evaluations but not the actual receipt of LDKT [21]. Together, these results suggest significant promise for an HCs approach that includes the patient's family, friends, and social network.

The Talking About Live Kidney Donation study features culturally sensitive LDKT educational materials offered with and without the assistance of a social worker to increase LDKT pursuit among AA CKD patients. The materials aim to increase the effectiveness with AAs by specifically addressing healthcare mistrust. The inclusion of family members in discussions between the patient and social worker is supported by the theory that AA patients 
may more easily explore the LDKT option if a family problem-solving approach is taken $[47,48]$, which like the HC approach separates the education from the healthcare system. Although the educational materials and social worker intervention compared to the usual care of LDKT education in nephrologists' offices were associated with taking additional steps toward LDKT, unfortunately the results were not stratified by race. As such, it is impossible to determine the intervention's effectiveness for AAs when compared to CAs [49]. A modified version of the Talking About Live Kidney Donation intervention is currently being tested with AA patients only [50].

The recent Reducing Disparities in Access to kidney Transplantation Community Study by Patzer et al. [51] demonstrated success in increased transplant referral rates among AA versus CA dialysis patients. The study used a multicomponent, multilevel intervention that incorporated transplant educational interactions with dialysis patients, the care team, and dialysis clinic leaders. The Social Ecological Model rationale for this intervention targets changing the patient's transplant knowledge and behaviors, as well as addressing barriers at the clinician and administration levels [51].

Other programs led by Waterman et al. $[52,53]$ based on the Transtheoretical Model of Behavior Change acknowledge AA dialysis and transplant patients' psychological and practical barriers work with individual patients in dialysis and transplant centers over multiple time points to increase stages of readiness for LDKT and DDKT. These programs have shown initial success in reducing racial disparities in transplant access, such as increasing living donor inquiries among AA compared to CA dialysis patients. However, the ultimate results of enhancing the education and transplant knowledge of dialysis patients are still being examined in multiple RCTs $[52,54]$.

Several other interventional studies to reduce racial disparities in kidney transplant between AAs and CAs have shown promising increases in knowledge about, or improved attitudes toward, transplant. Additionally, a prospective, observational study examining the effect of standardizing the transplant center evaluation education has increased rates of transplant evaluation completion with larger effects for AA than CA candidates [55]. Finally, other approaches have increased DDKT or LDKT evaluation and receipt. These approaches have not been designed to explicitly reduce racial disparities but might be adapted to do so. They include providing patients with a trained living donor champion or advocate to separate and remove the burden of making inquiries about living

Kidney Transplantation in AAss donation from the potential recipient [56], a call center that allows free, confidential, living-donation education with a trained former living donor [57], and using trained transplant recipients as patient navigators for dialysis patients [58].

Increase Research Studies with AAs and Other Ethnic Minorities Regarding Genetic Testing

There are 2 important areas where research regarding genetic testing may be further addressed: APOL1 gene variants and sickle cell disease (SCD). For example, the impact of testing for APOL1 gene variants has the potential to influence the practice of kidney transplantation in ways that are both beneficial and harmful and there is a strong opinion that additional studies are urgently needed in both DDKT and LDKT. Benefits of APOL1 testing include more accurate assessment of the quality of kidneys from deceased organ donors, thereby better guiding kidney allocation and acceptance policies. Potential harmful effects of APOL1 testing may include restricting access to living donation, exacerbating existing disparities, and causing psychological harm to donors with 2 APOL1 risk alleles. The APOL1 kidney risk variant is more common among individuals of African descent, but only some will develop clinical kidney disease in their lifetime. It is likely that additional genes and/or environmental factors interact with the APOL1 kidney risk variant to trigger CKD. In order to diminish the potentially negative impact on prospective donors, nephrologists should discuss the possible risks of carrying 2 APOL1 alleles.

Notably, the mechanisms by which genetic factors, environmental factors, and gene-environmental interactions affect CKD susceptibility are still unknown. Previous studies have focused on the differences in CKD by self-reported race, making it difficult to delineate the importance of environmental compared with biologic factors [59-61]. The National Institute of Diabetes and Digestive and Kidney Diseases recently issued a request for applications (RFA) entitled "APOL1 Long-term Kidney Transplantation Outcomes Network Clinical Centers" [62]. The RFA seeks investigator teams to conduct longitudinal cohort studies at multiple sites to examine the effect of APOL1 gene variants as risk factors for poor kidney transplant outcomes among recipients of kidneys from AA donors. This study will help determine the level of risk that APOL1 variants may have on adverse outcomes and help inform clinical decision-making about the suitability of APOL1 risk allele carriers for kidney donation. 
Testing for SCD has been shown to improve survival outcomes for kidney transplant recipients [63]. Most people with SCD are also of African ancestry or identify themselves as Black. In the United States, about 1 in 13 AA babies (8\%) are born with sickle cell trait, and 1 out of 400-500 AA newborns has the disease. The gene variant that causes SCD evolved as a result of malaria resistance. In the malaria belt regions of Africa, this gene variant flourished because the benefits of malaria resistance outweighed the negative impact of SCD. It is then common in African heritage because those geographic regions are most prone to malaria, but the gene variant for SCD is related to malaria, not skin color. Since organs available for transplantation are limited, the expansion of the eligibility criteria for deceased donation is of substantial interest. Prior studies have indicated that after 6 years, patient survival was lower among kidney transplant recipients with SCD compared to other diagnoses. However, recent studies have indicated improved survival; $69.8 \%$ versus early era, $p=$ 0.04 [49].

Genomic variation plays a large role in disease predisposition and drug response. Thus, it is important to develop tools for genomic variant discovery specifically in AAs, who have been underrepresented in many worldwide genetic diversity projects. Detection of selection signatures in the APOL1 gene can elucidate key evolutionarily conserved genomic regions and identify loss-offunction kidney protective mutations that may be demonstrated using model knockout orthologs. For example, a preliminary genetic risk stratification scheme, using 2 single nucleotide polymorphisms, may estimate lifetime risk for kidney disease [64]. Nevertheless, at present, no role has been established for genetic testing as part of personalized medicine, but testing should be considered in clinical studies of CKD patients among AAs. In addition, our knowledge of genetics should provide a heightened sense of awareness that current and future advances in medicine may have a different connotation for AAs. Indeed, transparency, regulatory accountability, and robust medical ethical frameworks should be instituted to protect the rights of patients against potentially powerful strategies to eradicate various risk factors in high risk AAs, which significantly impact renal transplantation outcomes.

\section{Policy-Level Interventions}

In addition to increased education about transplant and increased understanding of the role genetics play in suitability for kidney transplantation and donation, pol- icy-level interventions that address socioeconomic factors may also help increase access to, and outcomes of, kidney transplantation for AAs. Socioeconomic factors such as low incomes and poor quality health insurance currently serve as significant barriers to transplant for AAs [65-68]. An important policy that may address these factors includes the extension of health insurance benefits that cover the costs of transplant-related immunosuppressant medications for life. This policy could be cost effective, since it would improve kidney transplant graft survival and prevent returns to dialysis [69].

A recent AST Consensus Conference on Best Practices in Living Donation recommended that out-of-pocket costs for living donation be eliminated [39]. Since living kidney donation may require costs to travel, costs of meals, as well as the need to take time off of work, AAs without a great deal of financial flexibility may not be able to donate. Ensuring that these costs are covered for living donors would likely increase the number of AAs who are able to donate as well as increase the number of AAs who can receive a LDKT.

Policies outlined in the new KAS [70] may help increase access to kidney transplantation for AAs by reducing geographic disparities and improving limited allocation based on blood type. As a result of the new KAS, more frequent allocation of kidneys based on priority of higher calculated panel reactive antibodies and local and regional lists of kidneys with higher kidney donor profile index is expected. The new KAS may also increase the number of life years since transplantation by crediting time on dialysis prior to listing and prioritizing those with expected worse outcomes, such as increased cardiovascular risk factor burden.

\section{Conclusion}

There is a renewed awakening by healthcare agencies and patient advocates regarding healthcare disparities within the United States as it relates to kidney disease, of which AAs lead this trend across all factors associated with kidney transplantation. In order to sustain this momentum, there is a need to establish a transparent and trusted partnership between the AA, nephrology, and research communities with shared, achievable goals. Policies that facilitate timely referral and access to kidney transplantation, cultural awareness of the legacy of socioeconomic and historical racism, strategies to restore trust, reduce racial bias, improve patient engagement may also pave the
172

Am J Nephrol 2017;46:165-175

DOI: $10.1159 / 000479480$
Harding/Mersha/Pham/Waterman/

Webb/Vassalotti/Nicholas 
Table 1. Summary of barriers and accompanying interventions to address disparities in kidney transplantation for AAs

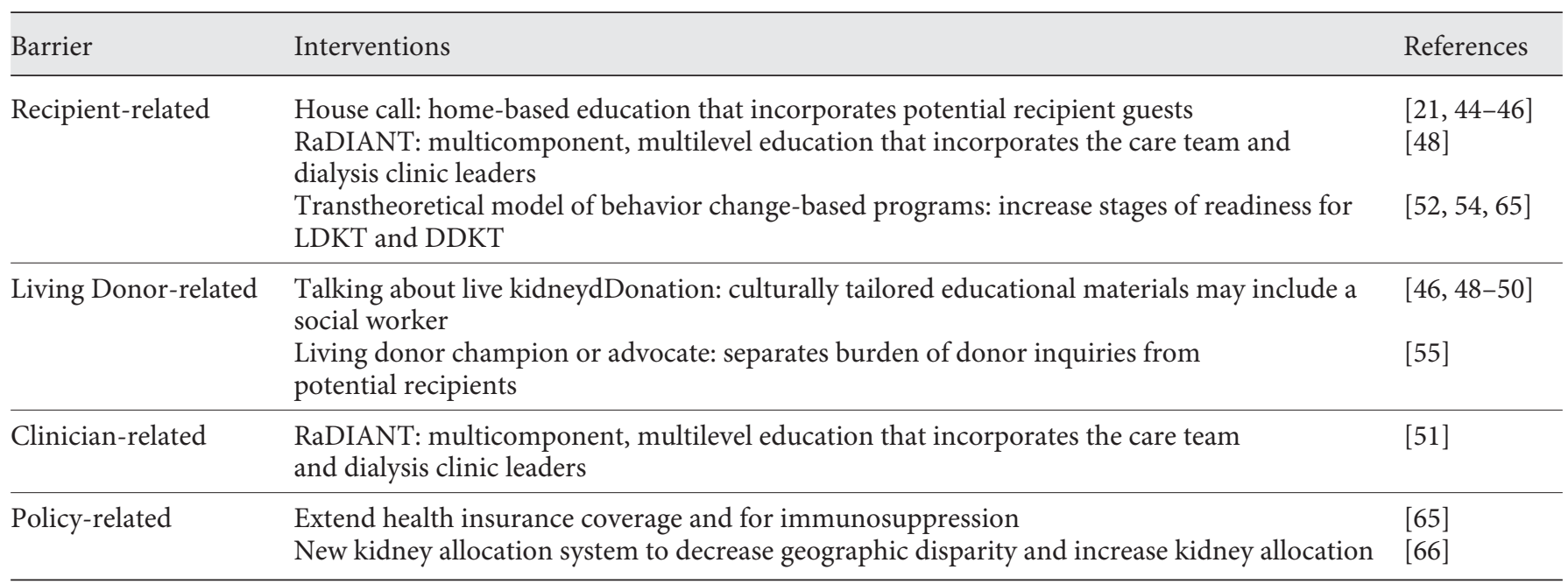

RaDIANT, reducing disparities in access to kidney transplantation community study; LDKT, living donor kidney transplant; DDKT, deceased donor kidney transplant.

way to reduce disparities within the healthcare system. Increased research opportunities to understand the impact of genetics, and greater participation in clinical research are important interventions. In addition, the adoption of strategies of new KAS as well as new performance-based care models and the expansion of precision medicine and biomarker research will provide essential predictive analytics to refine and improve the predictability of care for AA donors and recipients. The approaches summarized in Table 1 provide an actionable framework of interventional strategies.

\section{Acknowledgment}

This work was supported by NIH grant R01HL132344 to TBM; and NIH grants 1DP3 DK094311 and UL1TR000124 to SBN. The authors would also like to acknowledge Beverly Bobbitt for her contribution.

\section{Disclosure Statement}

The authors claim no conflicts of interest. The content is solely the responsibility of the authors and the authors declare that they have no relevant financial interests.

\section{References}

1 Malek SK, Keys BJ, Kumar S, Milford E, Tullius SG: Racial and ethnic disparities in kidney transplantation. Transpl Int 2011;24:419424.

-2 Saran R, Li Y, Robinson B, Ayanian J, Balkrishnan R, Bragg-Gresham J, Chen JT, Cope E, Gipson D, He K, Herman W, Heung M, Hirth RA, Jacobsen SS, Kalantar-Zadeh K, Kovesdy CP, Leichtman AB, Lu Y, Molnar MZ, Morgenstern H, Nallamothu B, O'Hare AM, Pisoni R, Plattner B, Port FK, Rao P, Rhee CM, Schaubel DE, Selewski DT, Shahinian V, Sim JJ, Song P, Streja E, Kurella Tamura M, Tentori F, Eggers PW, Agodoa LY, Abbott KC: US renal data system 2014 annual data report: epidemiology of kidney disease in the united states. Am J Kidney Dis 2015;66(1 suppl 1):Svii, S1-S305.
>3 Taber DJ, Gebregziabher M, Hunt KJ, Srinivas $\mathrm{T}$, Chavin $\mathrm{KD}$, Baliga PK, Egede LE: Twenty years of evolving trends in racial disparities for adult kidney transplant recipients. Kidney Int 2016;90:878-887.

-4 Epstein AM, Ayanian JZ, Keogh JH, Noonan SJ, Armistead N, Cleary PD, Weissman JS, David-Kasdan JA, Carlson D, Fuller J, Marsh D, Conti RM: Racial disparities in access to renal transplantation - clinically appropriate or due to underuse or overuse? N Engl J Med 2000;343:1537-1544, 1532 p preceding 1537.

$\checkmark 5$ Monson RS, Kemerley P, Walczak D, Benedetti E, Oberholzer J, Danielson KK: Disparities in completion rates of the medical prerenal transplant evaluation by race or ethnicity and gender. Transplantation 2015;99:236-242.
6 Schold JD, Buccini LD, Reese PP, Poggio ED, Goldfarb DA: Effect of dialysis initiation for preemptively listed candidates in the revised kidney allocation policy. Am J Transplant 2014;14:2855-2860.

$>7$ Reddan DN, Szczech LA, Klassen PS, Owen WF Jr: Racial inequity in America's esrd program. Semin Dial 2000;13:399-403.

$>8$ Leggat JE Jr, Bloembergen WE, Levine G, Hulbert-Shearon TE, Port FK: An analysis of risk factors for withdrawal from dialysis before death. J Am Soc Nephrol 1997;8:1755-1763.

$>9$ Salter ML, Kumar K, Law AH, Gupta N, Marks K, Balhara K, McAdams-DeMarco MA, Taylor LA, Segev DL: Perceptions about hemodialysis and transplantation among African American adults with end-stage renal disease: inferences from focus groups. BMC Nephrol 2015;16:49. 
10 Wachterman MW, McCarthy EP, Marcantonio ER, Ersek M: Mistrust, misperceptions, and miscommunication: a qualitative study of preferences about kidney transplantation among African Americans. Transplant Proc 2015;47:240-246.

$\checkmark 11$ Gillespie A, Hammer H, Lee J, Nnewihe C, Gordon J, Silva P: Lack of listing status awareness: results of a single-center survey of hemodialysis patients. Am J Transplant 2011;11: 1522-1526.

12 Davenport CB: The work of the eugenics record office. Eugen Rev 1923;15:313-315.

13 Price GN, Darity WA Jr: The economics of race and eugenic sterilization in North Carolina: 1958-1968. Econ Hum Biol 2010;8:261272.

14 Stern AM: Sterilized in the name of public health: Race, immigration, and reproductive control in modern California. Am J Public Health 2005;95:1128-1138.

15 Davis LA, Grogan TM, Cox J, Weng FL: Interand intrapersonal barriers to living donor kidney transplant among black recipients and donors. J Racial Ethn Health Disparities 2016, Epub ahead of print.

16 Lunsford SL, Simpson KS, Chavin KD, Menching KJ, Miles LG, Shilling LM, Smalls GR, Baliga PK: Racial disparities in living kidney donation: Is there a lack of willing donors or an excess of medically unsuitable candidates? Transplantation 2006;82:876-881.

17 Alnimri M, Laftavi MR, Kohli R, Said M, Feng L, Patel S, Pankewycz O: African-American women and older patients are at risk for a greater decline in renal function following living kidney donation. Transplant Proc 2011; 43:512-515.

18 Locke JE, Sawinski D, Reed RD, Shelton B, MacLennan PA, Kumar V, Mehta S, Mannon RB, Gaston R, Julian BA, Carr JJ, Terry JG, Kilgore M, Massie AB, Segev DL, Lewis CE: Apolipoprotein L1 and chronic kidney disease risk in young potential living kidney donors. Ann Surg 2017, Epub ahead of print.

19 Riella LV, Sheridan AM: Testing for high-risk apol1 alleles in potential living kidney donors. Am J Kidney Dis 2015;66:396-401.

20 http://www.kdigo.org/clinical_practice_ guidelines/LivingDonor (accessed March 3, 2017).

-21 Rodrigue JR, Paek MJ, Egbuna O, Waterman AD, Schold JD, Pavlakis M, Mandelbrot DA: Making house calls increases living donor inquiries and evaluations for blacks on the kidney transplant waiting list. Transplantation 2014;98:979-986.

-22 Fan PY, Ashby VB, Fuller DS, Boulware LE, Kao A, Norman SP, Randall HB, Young C, Kalbfleisch JD, Leichtman AB: Access and outcomes among minority transplant patients, 1999-2008, with a focus on determinants of kidney graft survival. Am J Transplant 2010;10(4 pt 2):1090-1107.

- 23 Foster CE 3rd, Philosophe B, Schweitzer EJ, Colonna JO, Farney AC, Jarrell B, Anderson L, Bartlett ST: A decade of experience with re- nal transplantation in African-Americans. Ann Surg 2002;236:794-804; discussion 804805.

24 Freedman BI, Julian BA, Pastan SO, Israni AK, Schladt D, Gautreaux MD, Hauptfeld V, Bray RA, Gebel HM, Kirk AD, Gaston RS, Rogers J, Farney AC, Orlando G, Stratta RJ, Mohan S, Ma L, Langefeld CD, Hicks PJ, Palmer ND, Adams PL, Palanisamy A, Reeves-Daniel AM, Divers J: Apolipoprotein L1 gene variants in deceased organ donors are associated with renal allograft failure. Am J Transplant 2015;15:1615-1622.

25 Bleyer AJ, Donaldson LA, McIntosh M, Adams PL: Relationship between underlying renal disease and renal transplantation outcome. Am J Kidney Dis 2001;37:1152-1161.

26 Chandraker A: The real world impact of APOL1 variants on kidney transplantation. Transplantation 2016;100:16-17.

27 Ojo A, Knoll GA: Apol1 genotyping of African American deceased organ donors: not just yet. Am J Transplant 2015;15:1457-1458.

28 https://www.cdc.gov/nchhstp/healthdisparities/africanamericans.html (accessed June 4, 2017).

29 Taber DJ, Egede LE, Baliga PK: Outcome disparities between African Americans and caucasians in contemporary kidney transplant recipients. Am J Surg 2017;213:666-672.

-30 Commodore-Mensah Y, Himmelfarb CD, Agyemang C, Sumner AE: Cardiometabolic health in African immigrants to the United States: a call to re-examine research on African-descent populations. Ethn Dis 2015;25: 373-380.

31 Morris AA, Kransdorf EP, Coleman BL, Colvin $\mathrm{M}$ : Racial and ethnic disparities in outcomes after heart transplantation: a systematic review of contributing factors and future directions to close the outcomes gap. J Heart Lung Transplant 2016;35:953-961.

32 Israni AK, Weng FL, Cen YY, Joffe M, Kamoun M, Feldman HI: Electronically measured adherence to immunosuppressive medications and kidney function after deceased donor kidney transplantation. Clin Transplant 2011;25:E124-E131.

33 Weng FL, Israni AK, Joffe MM, Hoy T, Gaughan CA, Newman M, Abrams JD, Kamoun M, Rosas SE, Mange KC, Strom BL, Brayman KL, Feldman HI: Race and electronically measured adherence to immunosuppressive medications after deceased donor renal transplantation. J Am Soc Nephrol 2005; 16:1839-1848.

- 34 Oetting WS, Schladt DP, Guan W, Miller MB, Remmel RP, Dorr C, Sanghavi K, Mannon RB, Herrera B, Matas AJ, Salomon DR, Kwok PY, Keating BJ, Israni AK, Jacobson PA; DeKAF Investigators: Genomewide association study of tacrolimus concentrations in African American kidney transplant recipients identifies multiple CYP3A5 alleles. Am J Transplant 2016;16:574-582.

35 Sanghavi K, Brundage RC, Miller MB, Schladt DP, Israni AK, Guan W, Oetting WS, Man- non RB, Remmel RP, Matas AJ, Jacobson PA: Genotype-guided tacrolimus dosing in African-American kidney transplant recipients. Pharmacogenomics J 2017;17:61-68.

36 Waterman AD, Rodrigue JR, Purnell TS, Ladin K, Boulware LE: Addressing racial and ethnic disparities in live donor kidney transplantation: priorities for research and intervention. Semin Nephrol 2010;30:90-98.

-37 Rodrigue JR, Kazley AS, Mandelbrot DA, Hays $\mathrm{R}$, LaPointe Rudow D, Baliga P: Living donor kidney transplantation: overcoming disparities in live kidney donation in the US - recommendations from a consensus conference. Clin J Am Soc Nephrol 2015;10:1687-1695.

38 Ladin K, Rodrigue JR, Hanto DW: Framing disparities along the continuum of care from chronic kidney disease to transplantation: barriers and interventions. Am J Transplant 2009;9:669-674.

39 LaPointe Rudow D, Hays R, Baliga P, Cohen DJ, Cooper M, Danovitch GM, Dew MA, Gordon EJ, Mandelbrot DA, McGuire S, Milton J, Moore DR, Morgievich M, Schold JD, Segev DL, Serur D, Steiner RW, Tan JC, Waterman $\mathrm{AD}$, Zavala EY, Rodrigue JR: Consensus conference on best practices in live kidney donation: recommendations to optimize education, access, and care. Am J Transplant 2015; 15:914-922

40 Frohlich KL, Potvin L: Transcending the known in public health practice: the inequality paradox: the population approach and vulnerable populations. Am J Public Health 2008;98:216-221.

41 Waterman AD, Peipert JD, Hyland SS, McCabe MS, Schenk EA, Liu J: Modifiable patient characteristics and racial disparities in evaluation completion and living donor transplant. Clin J Am Soc Nephrol 2013;8: 995-1002.

42 Kutner NG, Zhang R, Huang Y, Johansen KL: Impact of race on predialysis discussions and kidney transplant preemptive wait-listing. Am J Nephrol 2012;35:305-311.

43 Waterman AD, Robbins ML, Peipert JD: Educating prospective kidney transplant recipients and living donors about living donation: practical and theoretical recommendations for increasing living donation rates. Curr Transplant Rep 2016;3:1-9.

44 Rodrigue JR, Cornell DL, Lin JK, Kaplan B, Howard RJ: Increasing live donor kidney transplantation: a randomized controlled trial of a home-based educational intervention. Am J Transplant 2007;7:394-401.

45 Rodrigue JR, Pavlakis M, Egbuna O, Paek M, Waterman AD, Mandelbrot DA: The "house calls" trial: a randomized controlled trial to reduce racial disparities in live donor kidney transplantation: rationale and design. Contemp Clin Trials 2012;33:811-818.

46 Rodrigue JR, Cornell DL, Kaplan B, Howard RJ: A randomized trial of a home-based educational approach to increase live donor kidney transplantation: effects in blacks and whites. Am J Kidney Dis 2008;51:663-670. 
-47 DePasquale N, Hill-Briggs F, Darrell L, Boyer LL, Ephraim P, Boulware LE: Feasibility and acceptability of the TALK social worker intervention to improve live kidney transplantation. Health Soc Work 2012;37:234-249.

48 DePasquale N, Hill-Briggs F, Darrell L, Ephraim PL, Falcone B, Shafer C, Lewis-Boyer L, Boulware LE: The talking about live kidney donation (TALK) social worker intervention: putting it into practice. J Nephrol Soc Work 2013;37:13-18.

49 Boulware LE, Hill-Briggs F, Kraus ES, Melancon JK, Falcone B, Ephraim PL, Jaar BG, Gimenez L, Choi M, Senga M, Kolotos M, Lewis-Boyer L, Cook C, Light L, DePasquale N, Noletto T, Powe NR: Effectiveness of educational and social worker interventions to activate patients' discussion and pursuit of preemptive living donor kidney transplantation: a randomized controlled trial. Am J Kidney $\mathrm{Dis} 2013 ; 61: 476-486$.

-50 Strigo TS, Ephraim PL, Pounds I, Hill-Briggs F, Darrell L, Ellis M, Sudan D, Rabb H, Segev D, Wang NY, Kaiser M, Falkovic M, Lebov JF, Boulware LE: The talks study to improve communication, logistical, and financial barriers to live donor kidney transplantation in African Americans: protocol of a randomized clinical trial. BMC Nephrol 2015;16:160.

-51 Patzer RE, Paul S, Plantinga L, Gander J, Sauls L, Krisher J, Mulloy LL, Gibney EM, Browne T, Zayas CF, McClellan WM, Arriola KJ, Pastan SO; Southeastern Kidney Transplant Coalition: A randomized trial to reduce disparities in referral for transplant evaluation. J Am Soc Nephrol 2017;28:935-942.

52 Waterman AD, McSorley AM, Peipert JD, Goalby CJ, Peace LJ, Lutz PA, Thein JL: Explore transplant at home: a randomized control trial of an educational intervention to increase transplant knowledge for black and white socioeconomically disadvantaged dialysis patients. BMC Nephrol 2015;16:150.

- 53 Waterman AD, Morgievich M, Cohen DJ, Butt Z, Chakkera HA, Lindower C, Hays RE, Hiller JM, Lentine KL, Matas AJ, Poggio ED, Rees MA, Rodrigue JR, LaPointe Rudow D; American Society of Transplantation: Living donor kidney transplantation: Improving education outside of transplant centers about live donor transplantation - recommendations from a consensus conference. Clin J Am Soc Nephrol 2015;10:1659-1669.

54 Waterman $\mathrm{AD}$, Robbins ML, Paiva AL, Peipert JD, Kynard-Amerson CS, Goalby CJ, Davis LA, Thein JL, Schenk EA, Baldwin KA, Skelton SL, Amoyal NR, Brick LA: Your path to transplant: a randomized controlled trial of a tailored computer education intervention to increase living donor kidney transplant. BMC Nephrol 2014;15:166.

55 Patzer RE, Perryman JP, Pastan S, Amaral S, Gazmararian JA, Klein M, Kutner N, McClellan WM: Impact of a patient education program on disparities in kidney transplant evaluation. Clin J Am Soc Nephrol 2012;7:648-655.

56 Garonzik-Wang JM, Berger JC, Ros RL, Kucirka LM, Deshpande NA, Boyarsky BJ, Montgomery RA, Hall EC, James NT, Segev DL: Live donor champion: finding live kidney donors by separating the advocate from the patient. Transplantation 2012;93:1147-1150.

57 https://www.kidney.org/patients/peers (accessed January 25, 2017).

58 Sullivan C, Leon JB, Sayre SS, Marbury M, Ivers M, Pencak JA, Bodziak KA, Hricik DE, Morrison EJ, Albert JM, Navaneethan SD, Reyes CM, Sehgal AR: Impact of navigators on completion of steps in the kidney transplant process: a randomized, controlled trial. Clin J Am Soc Nephrol 2012;7:1639-1645.

59 Gutierrez OM, Isakova T, Smith K, Epstein M, Patel N, Wolf M: Racial differences in postprandial mineral ion handling in health and in chronic kidney disease. Nephrol Dial Transplant 2010;25:3970-3977.

60 Gutierrez OM, Parsa A, Isakova T, Scialla JJ, Chen J, Flack JM, Nessel LC, Gupta J, Bellovich KA, Steigerwalt S, Sondheimer JH, Wright JT Jr, Feldman HI, Kusek JW, Lash JP, Wolf M: Genetic African ancestry and markers of mineral metabolism in CKD. Clin J Am Soc Nephrol 2016;11:653-662.

61 Peralta CA, Lin F, Shlipak MG, Siscovick D, Lewis C, Jacobs DR Jr, Bibbins-Domingo K: Race differences in prevalence of chronic kid- ney disease among young adults using creatinine-based glomerular filtration rate-estimating equations. Nephrol Dial Transplant 2010; 25:3934-3939.

62 https://grants.nih.gov/grants/guide/rfa-files/ RFADK-16-025.html (accessed March 4, 2017).

63 Huang E, Parke C, Mehrnia A, Kamgar M, Pham PT, Danovitch G, Bunnapradist S: Improved survival among sickle cell kidney transplant recipients in the recent ERA. Nephrol Dial Transplant 2013;28:1039-1046.

64 Kopp JB, Winkler CA, Nelson GW: Myh9 genetic variants associated with glomerular disease: what is the role for genetic testing? Semin Nephrol 2010;30:409-417.

65 Waterman AD, Peipert JD, Goalby CJ, Dinkel KM, Xiao H, Lentine KL: Assessing transplant education practices in dialysis centers: comparing educator reported and medicare data. Clin J Am Soc Nephrol 2015;10:16171625.

66 Axelrod DA, Dzebisashvili N, Schnitzler MA, Salvalaggio PR, Segev DL, Gentry SE, TuttleNewhall J, Lentine KL: The interplay of socioeconomic status, distance to center, and interdonor service area travel on kidney transplant access and outcomes. Clin J Am Soc Nephrol 2010;5:2276-2288.

67 Schold JD, Gregg JA, Harman JS, Hall AG, Patton PR, Meier-Kriesche HU: Barriers to evaluation and wait listing for kidney transplantation. Clin J Am Soc Nephrol 2011;6: 1760-1767.

68 Patzer RE, Amaral S, Wasse H, Volkova N, Kleinbaum D, McClellan WM: Neighborhood poverty and racial disparities in kidney transplant waitlisting. J Am Soc Nephrol 2009;20:1333-1340.

69 Gill JS, Tonelli M: Penny wise, pound foolish? Coverage limits on immunosuppression after kidney transplantation. N Engl J Med 2012; 366:586-589.

70 Stegall MD, Stock PG, Andreoni K, Friedewald JJ, Leichtman AB: Why do we have the kidney allocation system we have today? A history of the 2014 kidney allocation system. Hum Immunol 2017;78:4-8. 